Article

\title{
Properties of the Iron Bacteria Biofouling on Ni-P-rGO Coating
}

\author{
Zhiming Xu, Mingyang Sun *, Zuodong Liu, Bingbing Wang and Huishuang Di
}

School of Energy and Power Engineering, Northeast Electric Power University, Jilin City 132012, China; xuzm@neepu.edu.cn (Z.X.); liuzuodong@neepu.edu.cn (Z.L.); wangbb@neepu.edu.cn (B.W.); dhs_0411@163.com (H.D.)

* Correspondence: sunmingyang0313@163.com

Received: 22 January 2020; Accepted: 21 February 2020; Published: 25 February 2020

\begin{abstract}
Biofouling on heat exchange devices can decrease heat transfer efficiency, corrode materials, and even lead to safety accidents. Most heat exchange devices are made of carbon steel that efficiently produces biofouling. However, in this paper, a nickel-phosphorus-reduced graphene oxide (Ni-P-rGO) coating was prepared on carbon steel by electroless plating to investigate the properties of iron bacteria biofouling. The surface coating was analyzed via scanning electron microscopy and Raman spectroscopy. After the carbon steel and the Ni-P-rGO coating were immersed into an iron bacteria solution for $120 \mathrm{~h}$, the weight of the iron bacteria biofouling on the Ni-P-rGO coating sharply decreased when compared with the carbon steel. We can conclude that the concentration of graphene can affect the weight of iron bacteria biofouling. We also found that the coating solution with $40 \mathrm{mg} / \mathrm{L}$ of graphene performed the best in inhibiting biofouling by decreasing the weight of the biofouling by $97.2 \%$ compared to carbon steel.
\end{abstract}

Keywords: biofouling; electroless; graphene; surface energy; DLVO theory; iron bacteria

\section{Introduction}

Biofouling is a biofilm or an organic film that is formed by bacteria, algae, and other microorganisms, as well as their excreta that are deposited on a solid surface [1]. Biofouling can lead to severe issues, such as decreased heat transfer efficiency, corroded materials, and even safety accidents, when present on the surfaces of heat exchangers, water distribution pipes, cooling towers, and other structures [2].

Currently, modified surfaces have been widely used in various industries because of their anti-fouling, anti-corrosion, and non-pollution properties. In the last twenty years, multiple studies have focused on the anti-biofouling properties of modified surfaces. Liu and Zhao. [3] found that a coating of Ni-P-poly tetrafluoroethylene (Ni-P-PTFE) with a surface energy in the $21-26 \mathrm{~mJ} / \mathrm{m}^{2}$ range exhibited an excellent antimicrobial property and reduced the Escherichia (XA90) adhesion by $95 \%$ compared with stainless steel 304. Liu et al. [4] and $\mathrm{Xu}$ et al. [5] studied the effect of electroless $\mathrm{Ni}-\mathrm{P}$ and $\mathrm{Ni}-\mathrm{Cu}-\mathrm{P}$ coatings on the biofouling of iron bacteria, respectively, and they demonstrated that $\mathrm{Ni}-\mathrm{P}$ and $\mathrm{Ni}-\mathrm{Cu}-\mathrm{P}$ coatings have excellent anti-fouling properties. Shao et al. [6] found that a silver coating could inhibit the attachment of Pseudomonas aeruginosa (PA01).

Recently, the efficiency of the coating materials has been improved; the addition of carbon materials into the Ni-P electroless plating solution has been shown to lead to a coating material with good wear resistance, corrosion resistance, and anti-fouling. Wu et al. [7] showed that an Ni-P-graphene oxide (Ni-P-GO) coating on a mild steel surface possessed the best anti-wear and microhardness properties when $40 \mathrm{mg} / \mathrm{L}$ of graphene oxide was added into an electroless plating solution. Matjie et al. [8] prepared a modified diamond-like carbon (DLC) coating that reduced the adhesion of an aluminum 
silicate deposit by $97 \%$ compared with uncoated stainless steel. Shao et al. [9] added graphene oxide to reinforce an Ni-P coating material to inhibit the adhesion of Staphylococcus aureus.

Graphene has been increasingly used as a carbon material because of its outstanding thermal conductivity, stability, and reduced dispersion. Though the dispersion of graphene is low, several studies have still prepared Ni-P-reduced graphene oxide (Ni-P-rGO) coatings via electroless plating. Yu et al. [10] fabricated graphene-enhanced Ni-P composite films and found that the G-Ni-P composite plating increased Vickers' hardness and Young's modulus values compared to an Ni-P coating. Lee et al. [11] prepared an Ni-P-diamond/graphene coating; the coating exhibited increased hardness, corrosion resistance, and wear resistance in a $3.5 \mathrm{wt} \% \mathrm{NaCl}$ solution compared with $\mathrm{Ni}-\mathrm{P} /$ diamond and $\mathrm{Ni}-\mathrm{P} /$ graphene coatings. However, limited work has been carried out on the inhibition of the biofouling of Ni-P-rGO coatings.

Though the application of a modified surface can decrease biofouling, the reaction mechanism has not yet been fully explored; furthermore, contradictive theses on the reaction mechanism are available in the literature. Dexter et al. [12] demonstrated that low-energy substrates attracted reduced numbers of marine bacteria, while high-energy substrates led to an increased presence of bacteria. Baier [13] proposed an optimal surface energy for decreasing biofouling. However, according to other studies, decreased biofouling could be detected on high-energy surfaces, with high-energy surfaces exhibiting a higher removal rate than low-energy surfaces. [14,15]. Hahnel et al. [16] reported that there was no significant relationship between surface energy and bacterial adhesion. Nowadays, more and more researchers are explaining the phenomenon through the idea that modified surfaces decrease biofouling via the extended DLVO theory [17-22], which is a theory of colloidal stability. Al-Janabi and Malayeri [17] demonstrated that the electron-donor component of surface energy was the key parameter of the biofouling trend and the surface properties that are associated with it. Azeredo et al. [18] found that several interactions exist among bacteria, surfaces, and water and that, if the sum of all the interaction components $\left(\Delta E_{132}^{T O T}\right)$ were negative, bacterial adhesion would take place. Zhao et al. [19] determined the optimal surface free energy components of a surface by applying the extended DLVO theory. A surface with an optimal surface free energy could minimize the adhesive force of bacteria. This optimal free-energy surface theory has been successfully applied to calcium sulfate [19] and aluminum silicate [9]. Liu and Zhao $[20,21]$ found that the $\gamma_{2}^{L W}$ and $\gamma_{2}^{-}$, which are the components of surface energy, remarkably affected the sum of all the interaction components $\left(\Delta E_{132}^{T O T}\right)$; therefore, the ratio of the Lifshitz-van der Waals surface component to electron donor surface component, which is called the CQ (Chen and Qi) ratio, can influence the bacterial adhesion: this finding further explained the regulation of microbial fouling sediment through the extended DLVO theory.

In this work, dispersed graphene was added into an electroless bath formulation of Ni-P to prepare the modified surface of an Ni-P-rGO coating. The influence of a novel coating material on the biofouling of iron bacteria was experimentally studied and discussed based on the extended DLVO theory.

\section{Experimental}

\subsection{Experimental Procedure}

(1) Prepare Ni-P-rGO coatings.

(2) Analyze the coating morphology.

(3) Measure the coating contact angle and calculate surface energy.

(4) Cultivate the iron bacteria.

(5) Conduct biofouling experiments.

\subsection{The Coating of $\mathrm{Ni}-\mathrm{P}-\mathrm{rGO}$}

The Ni-P-rGO coating material was prepared on A36 ( $\leq 0.20 \% \mathrm{Mn} \leq 1.4 \% \mathrm{Si} \leq 0.35 \% \mathrm{~S} \leq$ $0.045 \mathrm{P} \leq 0.045)$ carbon steel $(30 \times 30 \times 0.5 \mathrm{~mm})$ by electroless plating. Before the electroless plating, 
the substrates were polished with a 600 grit waterproof abrasive paper and an 800 grit one to make the surface smooth and flat, respectively. Then, the polished substrates were put into sulfuric acid with a concentration of $20 \%$ for $1 \mathrm{~min}$ to obliterate the rust. Finally, the substrates were put into sulfuric acid with a concentration of $10 \%$ for $1 \mathrm{~min}$ to activate their surfaces. The carbon steel substrates were washed with distilled water after each step. Table 1 reports the electroless bath formulation composition and operating conditions. The $\mathrm{pH}$ of the electroless bath solution was adjusted to 4.8 by adding ammonium hydroxide. Prior to the addition of the graphene into the bath solution, the graphene was mixed with a dispersant and shaken for $2 \mathrm{~h}$ with the ultrasonic cleaner to make it evenly dispersed in the bath solution. The electroless plating process lasted $100 \mathrm{~min}$, with the plating bath solution being replaced every $20 \mathrm{~min}$.

Table 1. The electroless bath solution composition and operating conditions.

\begin{tabular}{cc}
\hline Nickel Sulfate & $\mathbf{2 5} \mathrm{g} / \mathrm{L}$ \\
\hline Sodium Hypophosphite & $30 \mathrm{~g} / \mathrm{L}$ \\
Citric Acid & $15 \mathrm{~g} / \mathrm{L}$ \\
Lactic Acid & $16 \mathrm{~g} / \mathrm{L}$ \\
Sodium Acetate & $11 \mathrm{~g} / \mathrm{L}$ \\
Potassium Iodide & $0.01 \mathrm{~g} / \mathrm{L}$ \\
Graphene & $20-80 \mathrm{mg} / \mathrm{L}$ \\
OP-10 & Appropriate \\
pH & 4.8 \\
Temperature & $83^{\circ} \mathrm{C}$ \\
\hline
\end{tabular}

\subsection{Contact Angle and Surface Energy}

Contact angles were obtained by the sessile drop method with the data physics OCA-20 contact angle analyzer, which had an accuracy of $\pm 0.25^{\circ}$ [22]. By using distilled water, diiodomethane, and ethylene glycol as probes, every sample was measured six-to-ten times. The relationship between the contact angle of the probe liquids on a solid substrate and the surface energy is described as follows:

$$
\gamma_{L} \cos \theta=\gamma_{s}-\gamma_{S L}
$$

where $\gamma_{L}$ is the surface tension of the experimental liquids, $\theta$ is the contact angle, $\gamma_{S}$ is the solid surface energy, and the $\gamma_{S L}$ is the solid and liquid interfacial energy. The solid and liquid interfacial energy equation is the following:

$$
\gamma_{S L}=\gamma_{S}+\gamma_{L}-2\left(\sqrt{\gamma_{S}^{L W} \cdot \gamma_{L}^{L W}}+\sqrt{\gamma_{S}^{+} \cdot \gamma_{L}^{-}}+\sqrt{\gamma_{S}^{-} \cdot \gamma_{L}^{+}}\right.
$$

where $\gamma_{S}^{L W}$ and $\gamma_{L}^{L W}$ are the Lifshitz-van der waals apolar component of solid surface and the experimental liquid, respectively; $\gamma_{S}^{+}$and $\gamma_{S}^{-}$are the electron acceptor and the electron donor of the solid surface, respectively; and $\gamma_{L}^{+}$and $\gamma_{L}^{-}$are the electron acceptor and the electron donor of experimental liquid, respectively.

By combining Equations (1) and (2), we can obtain:

$$
\gamma_{L}(1+\cos \theta)=2\left(\sqrt{\gamma_{S}^{L W} \cdot \gamma_{L}^{L W}}+\sqrt{\gamma_{S}^{+} \cdot \gamma_{L}^{-}}+\sqrt{\gamma_{S}^{-} \cdot \gamma_{L}^{+}}\right)
$$

Surface energy can be seen as the sum of a Lifshitz-van der Waals apolar component $\gamma_{i}^{L W}$ and a Lewis acid-base polar component $\gamma_{i}^{A B}[23]$ :

$$
\gamma_{i}^{T O T}=\gamma_{i}^{L W}+\gamma_{i}^{A B}
$$


The acid-base polar component $\gamma_{i}^{A B}$ can be obtained by taking advantage of the relationship between the electron donor $\gamma_{i}^{-}$and the electron acceptor $\gamma_{i}^{+}$subcomponents:

$$
\gamma_{i}^{A B}=2 \sqrt{\gamma_{i}^{+} \gamma_{i}^{-}}
$$

In order to obtain the surface energy components $\left(\gamma_{S}^{L W}, \gamma_{S}^{-}\right.$, and $\left.\gamma_{S}^{+}\right)$of a solid, the contact angles on the solid and the surface tension components $\left(\gamma_{L}^{L W}, \gamma_{L}^{-}\right.$and $\left.\gamma_{L}^{+}\right)$of three selected liquids (distilled water, diiodomethane, and ethylene glycol) must be determined. The surface tension components of the three liquids are reported in Table 2.

Table 2. The three selected liquids and their surface tension components.

\begin{tabular}{cccccc}
\hline Surface Tension [24] & $\gamma_{L}[\mathrm{mN} / \mathrm{m}]$ & $\gamma_{L}^{L W}[\mathrm{mN} / \mathrm{m}]$ & $\gamma_{L}^{L W}[\mathrm{mN} / \mathrm{m}]$ & $\gamma_{L}^{+}[\mathrm{mN} / \mathrm{m}]$ & $\gamma_{L}^{-}[\mathrm{mN} / \mathrm{m}]$ \\
\hline Distilled water & 72.8 & 21.8 & 51.0 & 25.5 & 25.5 \\
\hline Diiodomethane & 50.8 & 50.8 & 0 & 0 & 0 \\
\hline Ethylene glycol & 48.0 & 29.0 & 19.0 & 1.92 & 47.0 \\
\hline
\end{tabular}

Table 3 reports the contact angles and surface energies among the three selected liquids and the different coating materials. It was found that with the increase of the graphene concentration, the contact angle of $\mathrm{H}_{2} \mathrm{O}$ and $\mathrm{C}_{2} \mathrm{H}_{6} \mathrm{O}_{2}$ increased as well. In contrast, the contact angle of $\mathrm{CH}_{2} \mathrm{I}_{2}$ was not influenced by the variation of the graphene concentration. In order to obtain the surface energy of bacteria, the suspension of iron bacteria was centrifuged. The centrifuged iron bacteria were then uniformly coated on a clean glass sheet and dried by air for $1 \mathrm{~h}$. Then, the contact angle of the iron bacteria membrane was measured.

Table 3. The contact angles and surface energies among the three selected liquids and the different coating materials.

\begin{tabular}{cccccccc}
\hline & \multicolumn{3}{c}{ Contact Angle $(\theta)$} & \multicolumn{3}{c}{ Surface Energy $\left(\mathrm{mJ} / \mathbf{m}^{\mathbf{2}}\right)$} \\
\cline { 2 - 7 } & $\mathbf{H}_{\mathbf{2}} \mathbf{O}$ & $\mathbf{C H}_{\mathbf{2}} \mathbf{I}_{\mathbf{2}}$ & $\mathbf{C}_{\mathbf{2}} \mathbf{H}_{\mathbf{6}} \mathbf{O}_{\mathbf{2}}$ & $\gamma^{\mathrm{LW}}$ & $\gamma^{+}$ & $\gamma^{-}$ & $\gamma^{\text {TOT }}$ \\
\hline Carbon steel & $80.6 \pm 0.9$ & $36.6 \pm 0.9$ & $56.6 \pm 1.4$ & 41.28 & 0.02 & 6.69 & 42.01 \\
\hline $\mathrm{Ni}-\mathrm{P}-\mathrm{rGO}_{20}$ & $85.1 \pm 0.9$ & $41.2 \pm 1.8$ & $60 \pm 1$ & 39.00 & 0.007 & 4.56 & 39.37 \\
\hline $\mathrm{Ni}-\mathrm{P}-\mathrm{rGO}_{30}$ & $86.5 \pm 1$ & $41.7 \pm 1.3$ & $64.5 \pm 2$ & 38.74 & 0.11 & 4.95 & 40.22 \\
\hline $\mathrm{Ni}-\mathrm{P}-\mathrm{rGO}_{40}$ & $87 \pm 1.5$ & $41 \pm 1$ & $66.5 \pm 2$ & 39.10 & 0.23 & 5.19 & 41.27 \\
\hline $\mathrm{Ni}-\mathrm{P}-\mathrm{rGO}_{50}$ & $88.2 \pm 1.2$ & $42.4 \pm 2.1$ & $67.3 \pm 2.2$ & 38.50 & 0.21 & 4.65 & 40.46 \\
\hline $\mathrm{Ni}-\mathrm{P}-\mathrm{rGO}_{60}$ & $89.2 \pm 2.3$ & $41.2 \pm 1.8$ & $68.5 \pm 2.5$ & 39.00 & 0.29 & 4.31 & 41.25 \\
\hline $\mathrm{Ni}-\mathrm{P}-\mathrm{rGO}$ & $89.9 \pm 1.1$ & $41.2 \pm 1.8$ & $69.5 \pm 2$ & 39.00 & 0.35 & 4.14 & 41.41 \\
\hline Ni-P-rGO & $90.9 \pm 1.1$ & $41.2 \pm 2.7$ & $70.1 \pm 0.9$ & 39.00 & 0.36 & 3.70 & 41.32 \\
\hline Iron bacteria & $30.5 \pm 1.5$ & $38.3 \pm 1.2$ & $48.9 \pm 1.1$ & 40.45 & 0.81 & 71.20 & 55.63 \\
\hline
\end{tabular}

\subsection{Biofouling}

In this study, the iron bacteria were isolated and purified from the bottom sludge of the circulating cooling tower in a domestic power plant [25]. Before inoculating the iron bacteria, the medium was prepared (Table 4). Then, the medium was sterilized by autoclave for $30 \mathrm{~min}$. After inoculation, the medium was put into the incubator for $72 \mathrm{~h}$ at $30^{\circ} \mathrm{C}$. The samples of the carbon steel and the Ni-P-rGO coating material with the different concentrations of graphene $(20,30,40,50,60,70$, and $80 \mathrm{mg} / \mathrm{L}$ ) were submerged in an iron bacteria suspension for $120 \mathrm{~h}$. Thus, the carbon steel and the $\mathrm{Ni}-\mathrm{P}-\mathrm{rGO}$ coating were taken out and dried by air for $12 \mathrm{~h}$. After being dried by air, the samples were 
weighed by an electronic balance with an accuracy of $10^{-4}$. Then, the cleaned and dried samples were weighed again. Finally, the weight of the iron bacteria biofouling was calculated. Every graphene concentration sample was prepared in three replicas.

Table 4. The medium composition of iron bacteria.

\begin{tabular}{cc}
\hline Ammonium Ferric Citrate & $10 \mathrm{~g} / \mathrm{L}$ \\
\hline Sodium nitrate & $0.5 \mathrm{~g} / \mathrm{L}$ \\
\hline Dipotassium phosphate & $0.5 \mathrm{~g} / \mathrm{L}$ \\
\hline Calcium chloride & $0.2 \mathrm{~g} / \mathrm{L}$ \\
\hline Magnesium sulfate & $0.5 \mathrm{~g} / \mathrm{L}$ \\
\hline Ammonium sulfate & $0.5 \mathrm{~g} / \mathrm{L}$ \\
\hline $\mathrm{pH}$ & 6.8 \\
\hline
\end{tabular}

\section{Results}

\subsection{Morphology}

Figure 1 displays the morphologies of the carbon steel and the Ni-P-rGO coating that were determined via scanning electron microscopy (SEM). The Ni-P-rGO coating showed a higher flatness than the carbon steel in the microstructure, whereas there were many inlaid nodules in the Ni-P-rGO coating: This confirmed the presence of graphene that had a high specific surface area to stimulate the nucleation [11]. To further prove the existence of graphene, the Ni-P-rGO coating was detected via Raman spectroscopy.

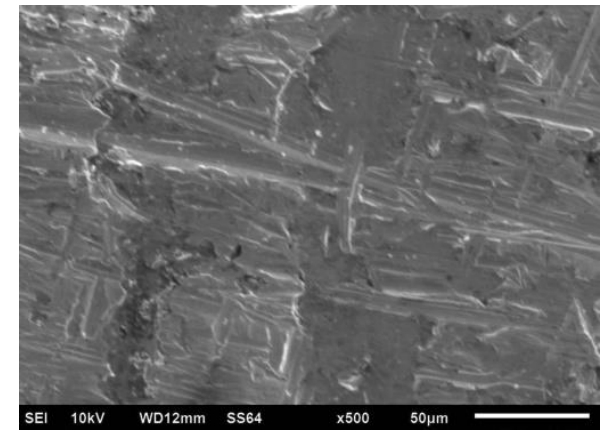

Carbon steel

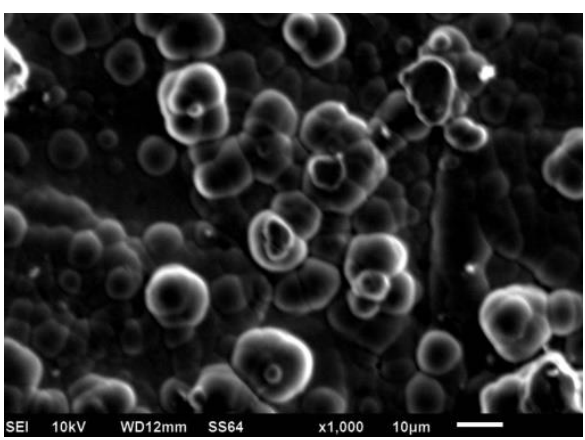

SEM 1000 of Ni-P-rGO coating

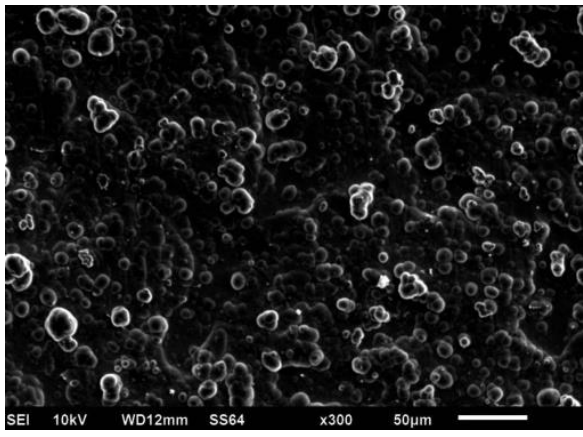

SEM 300 of $\mathrm{Ni}-\mathrm{P}-\mathrm{rGO}$ coating

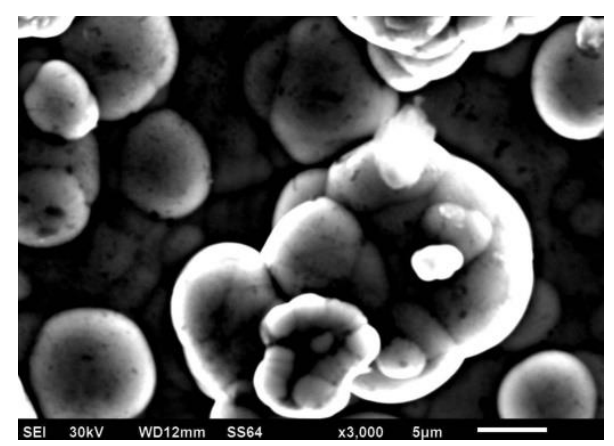

SEM 3000 of Ni-P-rGO coating

Figure 1. SEM morphology of the carbon steel and the nickel-phosphorus-reduced graphene oxide (Ni-P-rGO) coating. 
The Raman spectrum of the Ni-P-rGO coating is reported in Figure 2. It can be seen from Figure 2 that three evident peaks can be observed at 1350,1580, and $2700 \mathrm{~cm}^{-1}$, which correspond to the D band, the $\mathrm{G}$ band, and the $2 \mathrm{D}$ band. The $\mathrm{D}$ band can be assigned to the breathing mode of the k-point phonons with $A_{1 g}$ symmetry [26] and it is associated with the edge defects of graphene. The $G$ band introduced the $\mathrm{E}_{2 \mathrm{~g}}$ phonon of the carbon $\mathrm{sp}^{2}$ atoms and was caused by the highly ordered graphite [27]. The $2 \mathrm{D}$ band was generated by double phonon double resonance, which is closely related to the band structure of graphene [28].

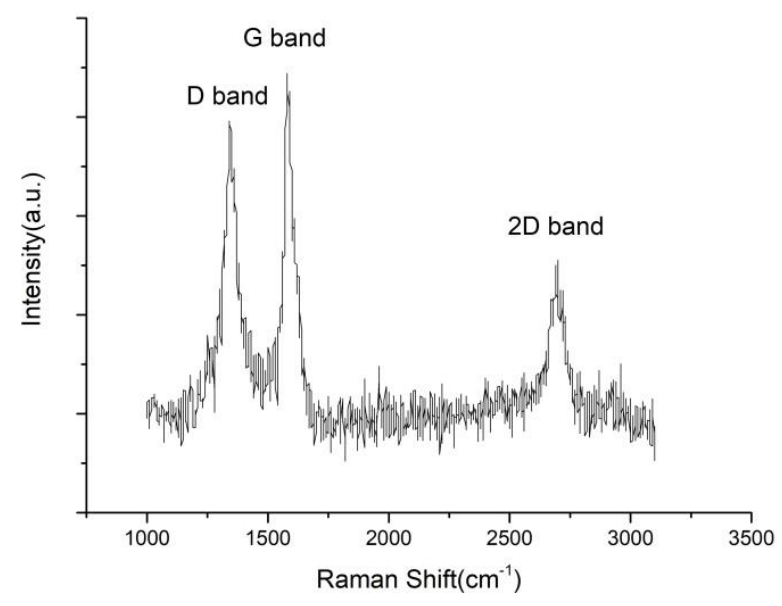

Figure 2. The Raman spectrum of rGO in the Ni-P-rGO coatings.

\subsection{The Weight of Biofouling on Carbon Steel and Ni-P-rGO Coating}

Figure 3 shows the macrograph and the micrograph of the carbon steel and one of the Ni-P-rGO coating after the experiments. A thicker layer of iron bacteria biofouling could be observed on the surface of the carbon steel, and there was a significant iron bacteria colony. However, it can be seen on the macrograph and micrograph that, on the coating of the Ni-P-rGO, biofouling was almost absent.

The iron bacteria biofouling weights on the carbon steel surface and the Ni-P-rGO coatings with different graphene contents are shown in Figure 4. The Ni-P-rGO coatings at different concentrations of graphene could remarkably inhibit the iron bacteria biofouling when compared to carbon steel. The presence of iron in the carbon steel provided nutrients for the iron bacteria, leading to enhanced biofouling.

Figure 5 depicts the relationship between the graphene concentration and the weight of the biofouling sediment. This figure clearly shows that with the increasing graphene concentration, the biofouling weight first decreased and then increased. At a graphene concentration of $40 \mathrm{mg} / \mathrm{L}$, the weight of the iron bacteria biofouling was reduced by $97.2 \%$ compared to the carbon steel. 


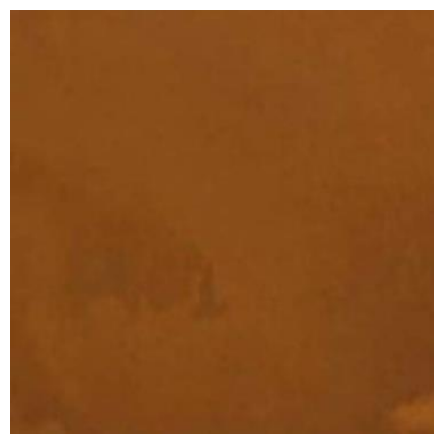

Macrograph of the carbon steel surface

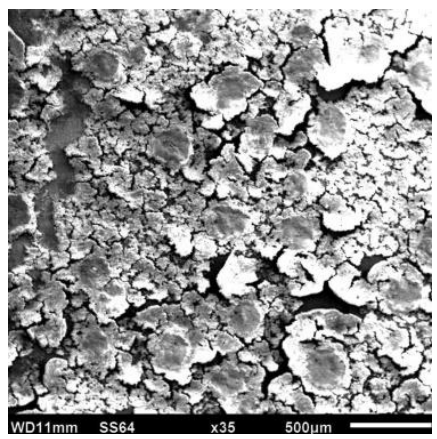

Micrograph of the carbon steel surface

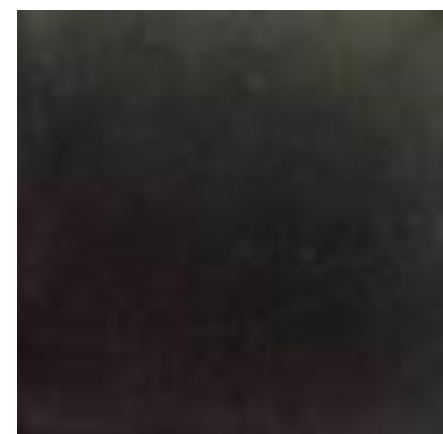

Micrograph of the coating surface

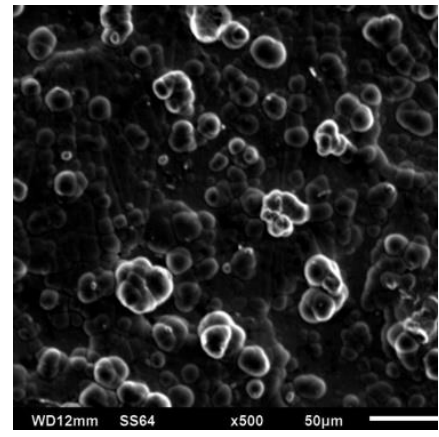

Micrograph of the coating surface

Figure 3. Macrographs and micrographs of the carbon steel surface and of the coating surface after experiments.

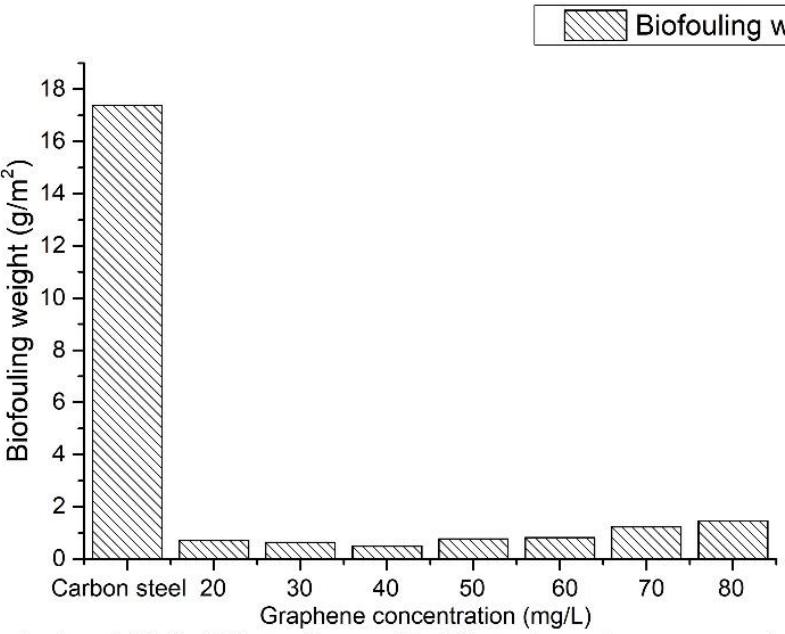

Carbon steel and Ni-P-rGO coatings with different graphene concentrations

Figure 4. The iron bacteria biofouling weight of the carbon steel and the Ni-P-rGO coatings. 


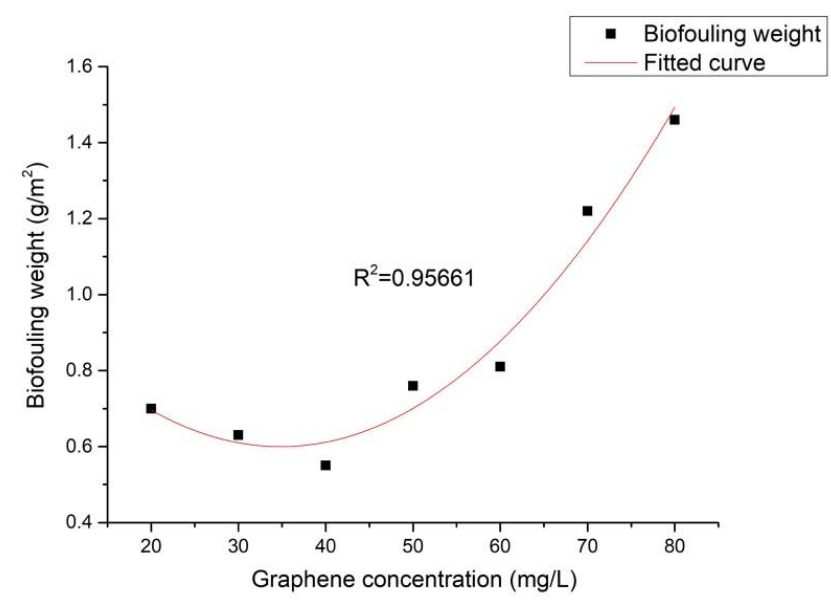

Figure 5. Effect of graphene concentration on the weight of the iron bacteria biofouling.

\subsection{Effect of the Surface Energy Component on the Biofouling of Iron Bacteria}

$\gamma^{-}$and $\gamma^{+}$are the electron-donor and the electron-acceptors of the surface energy component. From Table 3, it can be seen that the $\gamma_{S}^{-}$values of the Ni-P-rGO coating materials were much higher than those of $\gamma_{S}^{+}$, which were close to zero. The dependence of $\gamma_{S}^{-}$on the graphene concentration is shown in Figure 6. It was found that $\gamma_{S}^{-}$first increased and then decreased with the increase of the graphene concentration, reaching its maximum at the graphene concentration of $40 \mathrm{mg} / \mathrm{L}$. The effect of the surface energy component $\gamma_{S}^{-}$on the weight of the iron bacteria biofouling is illustrated in Figure 7. It can be observed that the weight of the iron bacteria biofouling decreased with the surface energy component $\gamma_{S}^{-}$. From Figures 6 and 7, it can be seen that the minimum and maximum weights of biofouling could be found for the Ni-P-rGO coating materials that contained 40 and $80 \mathrm{mg} / \mathrm{L}$ of graphene. The other Ni-P-rGO coating materials followed the same trend: When the $\mathrm{Ni}-\mathrm{P}-\mathrm{rGO}$ coating had a high electron donor component, the weight of the iron bacteria biofouling was small. Taking calcium carbonate as an example, Chibowski et al. [29] found that the electron donor $\gamma_{S}^{-}$and zeta potential could affect the charge of the surface. With the increase of the electron donor $\gamma_{S}^{-}$, the zeta potential decreased; furthermore, a higher $\gamma_{S}^{-}$corresponded to a more negatively charged surface. At the same time, because the isoelectric point of bacteria is $\mathrm{pH} 2-5$ and the $\mathrm{pH}$ of the experimental environment was higher than 5 , the surface of the bacteria released a negative charge. This explains the experimental phenomenon the weight of biofouling decreased when the electron donor $\gamma_{S}^{-}$value increased.

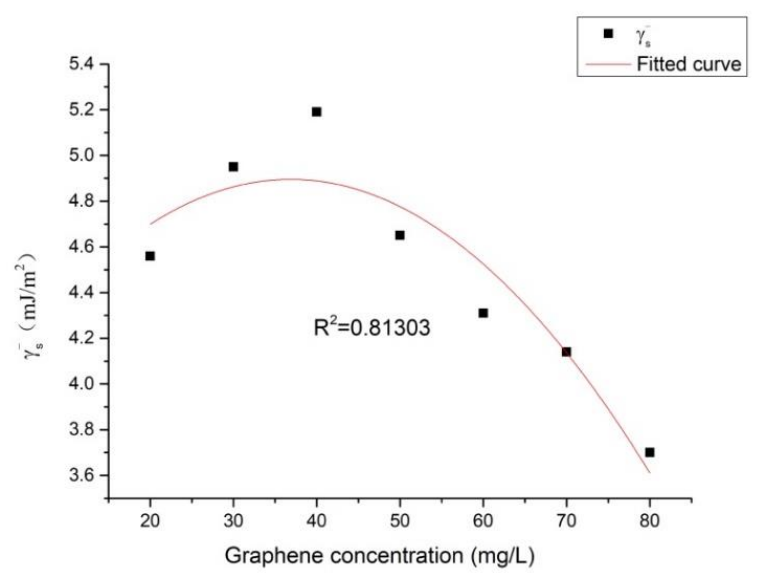

Figure 6. Dependence of the electron donor of the solid surface $\left(\gamma_{S}^{-}\right)$on the graphene concentration. 


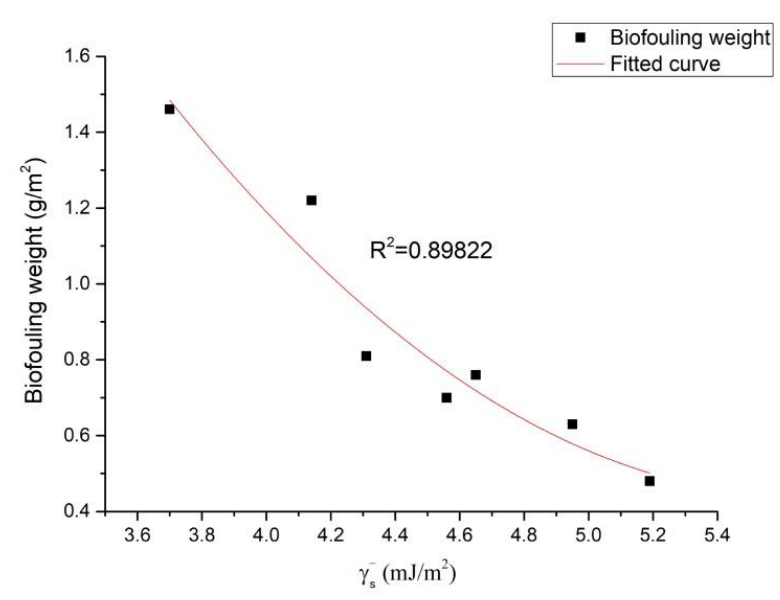

Figure 7. Effect of the surface energy component on the weight of the iron bacteria biofouling.

\section{Discussion}

Though there have been some reports about iron bacteria biofouling on electroless plating coatings, their reaction mechanisms have rarely been discussed [4,5]. Azeredo et al. [18] stated that there were four interaction energy components that were involved in the mechanism: the interaction between the bacteria and the substrate, the one between the bacteria and the solution, the one between the substrate and the solution, and biofouling adhesion, which consists of the combination of the three interactions, $\Delta E_{132}^{T O T}$. In other words, bacterial adhesion occurs if the total interaction energy $\Delta E_{132}^{T O T}$ is negative; furthermore, with the decrease of the $\Delta E_{132}^{T O T}$ value, bacterial adhesion increases.

$$
\Delta E_{132}^{T O T}=\Delta E_{132}^{L W}+\Delta E_{132}^{E L}+\Delta E_{132}^{A B}+\Delta E_{132}^{B r}
$$

From Equation (6), it can be seen that the four kinds of interaction energy among bacteria (1), substrates (2) and solutions (3) are the Lifshitz-van der Waals (LW) component, the electrostatic double-layer (EL) component, the Lewis acid-base component (AB), and the Brownian motion (Br) component. The four kinds of interaction energies are calculated as follows, respectively:

$$
\begin{gathered}
\Delta E_{132}^{L W}=-\frac{24 \pi H_{0}^{2}\left(\sqrt{\gamma_{1}^{L W}}-\sqrt{\gamma_{3}^{L W}}\right)\left(\sqrt{\gamma_{2}^{L W}}-\sqrt{\gamma_{3}^{L W}}\right) \cdot R}{6 H} \\
\Delta E_{132}^{E L}=\pi \cdot \varepsilon_{0} \cdot \varepsilon_{r} \cdot R \cdot\left(\zeta_{1}^{2}+\zeta_{2}^{2}\right) \times\left[\frac{2 \cdot \zeta_{1} \cdot \zeta_{2}}{\zeta_{1}^{2}+\zeta_{2}^{2}} \cdot \ln \frac{1+\exp (\kappa \cdot H)}{1-\exp (\kappa \cdot H)}+\ln \{1-\exp (-2 \cdot \kappa \cdot H)\}\right] \\
\Delta E_{132\left(H_{0}\right)}^{A B}=2\left[\sqrt{\gamma_{3}^{+}} \cdot\left(\sqrt{\gamma_{1}^{-}}+\sqrt{\gamma_{2}^{-}}-\sqrt{\gamma_{3}^{-}}\right)+\sqrt{\gamma_{3}^{-}} \cdot\left(\sqrt{\gamma_{1}^{+}}+\sqrt{\gamma_{2}^{+}}-\sqrt{\gamma_{3}^{+}}\right)-\sqrt{\gamma_{1}^{+} \gamma_{2}^{-}}-\sqrt{\gamma_{1}^{-} \gamma_{2}^{+}}\right] \\
\Delta E_{132}^{B r}=0.414 \times 10^{-20} J
\end{gathered}
$$

where $\gamma^{L W}, \gamma^{-}$, and $\gamma^{+}$are the surface energy components of the Lifshitz-van der Waals forces, the electron-acceptor, and the electron-donor, which can be calculated via the contact angles; $H$, which is the separation distance between the bacteria and the substrate [20], is assumed to be around $4 \mathrm{~nm}$; $H_{0}$ is the minimum equilibrium distance and is $0.157 \mathrm{~nm}$ [20]; $R$ is the radius of the bacteria and is $0.65 \mu \mathrm{m} \mathrm{[20];} \varepsilon_{0}$ is the electrical permittivity under the vacuum and is $8.85 \times 10^{-12} \mathrm{~J} \cdot \mathrm{m}^{-2} \cdot \mathrm{V}^{-2} ; \varepsilon_{r}$ is the relative dielectric permittivity of water, which is 78.54 [20]; $\kappa$ is the Debye-Hückel parameter (with $1 / \kappa=1.1 \mathrm{~nm})[20] ; \zeta_{1}$ and $\zeta_{2}$ are the zeta potentials of the bacteria $(-15 \mathrm{mV})$ and substrate $(-25 \mathrm{mV})$, respectively [20]; and $\lambda$ is the correlation length of the molecules of the liquid medium, which is in the range of $0.2-1.0 \mathrm{~nm}[20,30]$. 
According to the experimental and modeling results, $\Delta E_{132}^{T O T}$ had a high correlation to the ratio of $\gamma_{2}^{L W}$ to $\gamma_{2}^{-}$. The ratio of $\gamma_{2}^{L W}$ to $\gamma_{2}^{-}$was defined as the CQ ratio by Chen and Zhao [19,20], and it can be used to estimate whether biofouling more easily deposits. When the $\gamma_{1}^{L W}$ and $\gamma_{2}^{L W}$ values are both higher than $\gamma_{3}^{L W}$, the $\Delta E_{132}^{T O T}$ value increases with a decreasing CQ ratio.

$$
\text { CQratio }=\gamma_{2}^{L W} / \gamma_{2}^{-}
$$

The effect of graphene concentration on the CQ ratio is shown in Figure 8. As seen in Figure 8, with the increase of the graphene concentration, the CQ ratio first decreased then increased, in agreement with the trend illustrated in Figure 5. Figure 9 displays the effect of the CQ ratio on the weight of the iron bacteria biofouling. There, it could be observed that the coating with a lower CQ ratio exhibited a better property of decreasing bacterial adhesion; the correlation between these two phenomena was high, indicating that the graphene concentration could affect the CQ ratio of the surface and, thus, the weight of biofouling. Moreover, a directly proportional relationship between the CQ ratio and the weight of biofouling could be determined. This phenomenon was consistent with the extended DLVO theory.

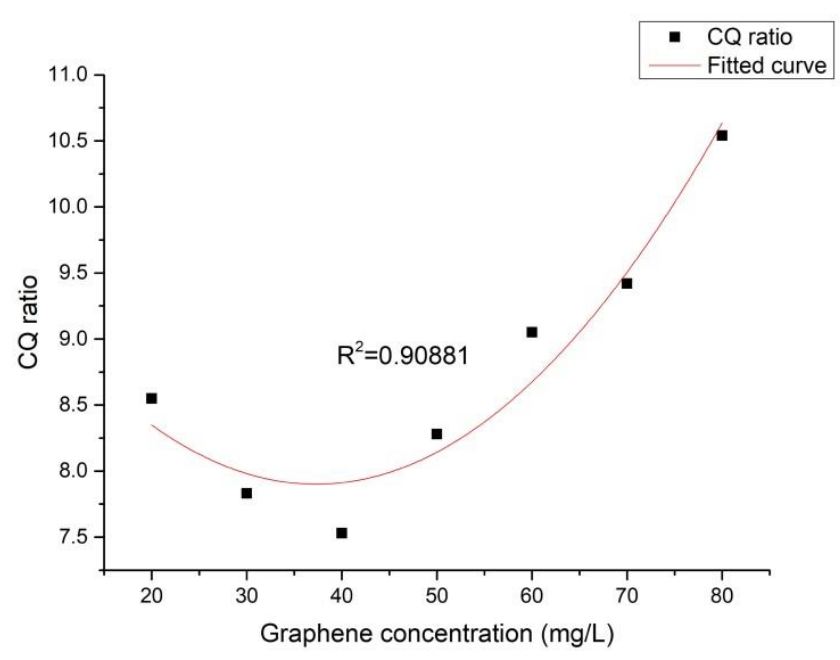

Figure 8. Effect of the graphene concentration on the CQ ratio.

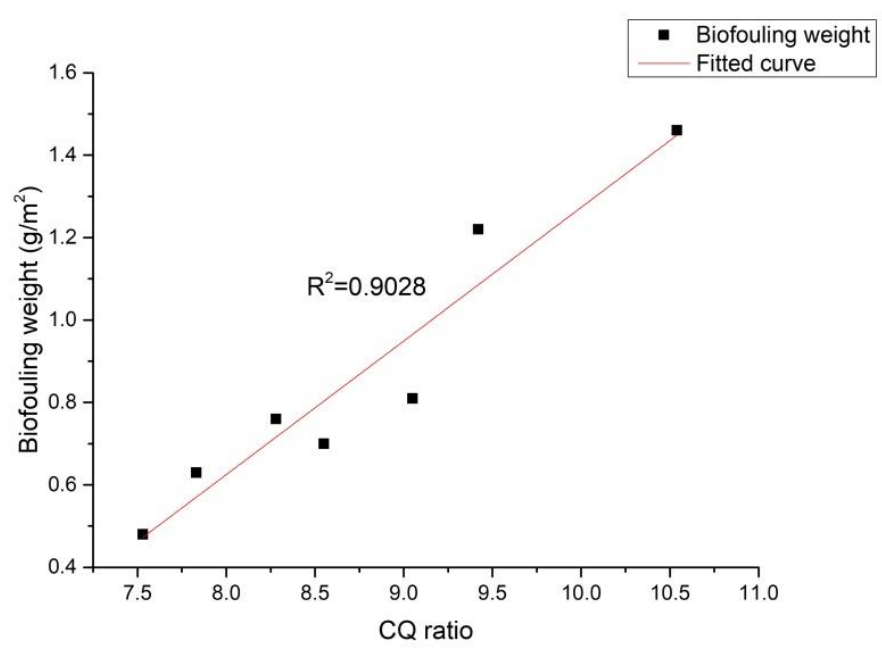

Figure 9. Effect of the CQ ratio on the weight of the iron bacteria biofouling. 


\section{Conclusions}

(1) In comparison with the carbon steel, the Ni-P-rGO coating exhibited an excellent property of inhibiting the biofouling of iron bacteria, with the $\left(\mathrm{Ni}-\mathrm{P}-\mathrm{rGO}_{40}\right)$ coating reducing the biofouling sediment by $97.2 \%$.

(2) The biofouling sediment on the Ni-P-rGO coating showed the following trend: With the increase of the graphene concentration, the weight of biofouling first decreased and then increased. When increasing the amount of graphene from 20 to $40 \mathrm{mg} / \mathrm{L}$, the weight of biofouling decreased to $21.4 \%$; however, as the concentration of graphene ranged from 40 to $80 \mathrm{mg} / \mathrm{L}$, the biofouling increased to $165.5 \%$.

(3) Graphene concentration can affect the CQ ratio of an Ni-P-rGO coating, thus affecting the weight of iron bacteria biofouling.

Author Contributions: Conceptualization, Z.X.; Data curation, Z.X. and M.S.; Formal analysis, Z.X., M.S., and Z.L.; Investigation, M.S., and B.W.; Methodology, Z.X. and M.S.; Project administration, Z.X.; Resources, Z.X.; Supervision, Z.X., Z.L., and H.D.; Validation, M.S., Z.L., B.W., and H.D.; Writing-original draft preparation, M.S.; Writing-review and editing, Z.X., Z.L., B.W., and H.D. All authors have read and agreed to the published version of the manuscript.

Funding: This research was funded by National Natural Science Foundation of China, grant number 51976028.

Acknowledgments: The financial support of the National Natural Science Foundation of China (grant no. 51976028) was gratefully acknowledged.

Conflicts of Interest: The authors declare no conflicts of interest.

\section{References}

1. Yang, S.R.; Xu, Z.M.; Sun, L.F. Fouling and Counter Measures for Heat Transfer Equipment, 2nd ed.; Science Press: Beijing, China, 2004.

2. Li, B.; Logan, B.E. Bacterial adhesion to glass and metal-oxide surfaces. Colloids Surf. B 2004, 36, 81-90. [CrossRef] [PubMed]

3. Liu, Z.D.; Yao, X.; Bai, W.Y.; Xu, Z.M. Effect of electroless Ni-P alloy coating on biofouling of iron bacteria. J. Eng. Therm. Energy Power 2016, 60, 4858-4865.

4. Liu, Y.; Zhao, Q. Influence of surface energy of modified surfaces on bacterial adhesion. Biophys. Chem. 2005, 117, 39-45. [CrossRef] [PubMed]

5. Xu, Z.M.; Wang, D.; Kong, L.W.; Liu, Z.D. Fouling characteristics of iron bacteria on the surface of electroless plating of Ni-Cu-P. Huagong Jinzhan 2017, 2. [CrossRef]

6. Shao, W.; Zhao, Q. Effect of corrosion rate and surface energy of silver coatings on bacterial adhesion. Colloids Surf. B 2010, 76, 98-103. [CrossRef]

7. Wu, H.H.; Liu, F.; Gong, W.B.; Ye, F.Y.; Hao, L.F.; Jiang, J.B.; Han, S. Preparation of Ni-P-GO composite coatings and its mechanical properties. Surf. Coat. Technol. 2015, 272, 25-32. [CrossRef]

8. Matjie, R.; Zhang, S.; Zhao, Q.; Mabuza, N.; Bunt, J.R. Tailored surface energy of stainless steel plate coupons to reduce the adhesion of aluminium silicate deposit. Fuel 2016, 181, 573-578. [CrossRef]

9. Shao, W.; Wu, J.M.; Liu, H.; Dong, G.H.; Wang, S.X.; Min, H.H.; Huang, M. Graphene oxide reinforced Ni-P coatings for bacterial adhesion inhibition. RSC Adv. 2016, 6, 46270. [CrossRef]

10. Qian, Y.; Zhou, T.F.; Jiang, Y.G.; Yan, X.; An, Z.L.; Wang, X.B.; Zhang, D.Y.; Ono, T. Preparation of graphene-enhanced nickel-phosphorus composite films by ultrasonic-assisted electroless plating. Appl. Surf. Sci. 2018, 435, 617-625.

11. Lee, C.K.; Teng, C.L.; Tan, A.H.; Yang, C.Y.; Lee, S.L. Electroless Ni-P/Diamond/Graphene composite coatings and characterization of their wear and corrosion resistance in sodium chloride solution. Key Eng. Mater. 2015, 656, 51-56. [CrossRef]

12. Dexter, S.C.; Sullivan, J.D.; Williams, J.; Watson, S.W. Influence of substrate wettability on the attachment of marine bacteria to various surfaces. Appl. Microbiol. 1975, 30, 298-308. [CrossRef] [PubMed]

13. Baier, R.E. Adsorption of Micro-Organism to Surface; Wiley Interscience: Hoboken, NJ, USA, 1980. 
14. Brink, L.E.S.; Elbers, S.J.G.; Robertsen, T.; Both, P. The anti-fouling action of polymers preadsorbed on ultrafiltration and microfiltration membranes. J. Membr. Sci. 1993, 76, 281-291. [CrossRef]

15. Pasmore, M.; Todd, P.; Smith, S.; Baker, D.; Silverstein, J.; Coons, D.; Bowman, C.N. Effects of ultrafiltration membrane surface properties on Pseudomonas aeruginosa biofilm initiation for the purpose of reducing biofouling. J. Membr. Sci. 2001, 194, 15-32. [CrossRef]

16. Hahnel, S.; Rosentritt, M.; Handel, G.; Bürgers, R. Surface characterization of dental ceramics and initial streptococcal adhesion in vitro. Dent. Mater. 2009, 25, 969-975. [CrossRef] [PubMed]

17. Al-Janabi, A.; Malayeri, M.R. A criterion for the characterization of modified surfaces during crystallization fouling based on electron donor component of surface energy. Chem. Eng. Res. Des. 2015, 100, 212-227. [CrossRef]

18. Azeredo, J.; Visser, J.; Oliveira, R. Exopolymers in bacterial adhesion: Interpretation in terms of DLVO and XDLVO theories. Colloids Surf. B 1999, 14, 141-148. [CrossRef]

19. Zhao, Q.; Liu, Y.; Wang, C.; Wang, S.; Müller-Steinhagen, H. Effect of surface free energy on the adhesion of biofouling and crystalline fouling. Chem. Eng. Sci. 2005, 60, 4858-4865. [CrossRef]

20. Liu, C.; Zhao, Q. The CQ ratio of surface energy components influences adhesion and removal of fouling bacteria. Biofouling 2011, 27, 275-285. [CrossRef]

21. Liu, C.; Zhao, Q. Influence of surface-energy components of $\mathrm{Ni}-\mathrm{P}-\mathrm{TiO}_{2}-\mathrm{PTFE}$ nanocomposite coatings on bacterial adhesion. Langmuir 2011, 27, 9512-9519. [CrossRef]

22. Tavana, H.; Simon, F.; Grundke, K.; Kwok, D.Y.; Hair, M.L.; Neumann, A.W. Interpretation of contact angle measurements on two different fluoropolymers for the determination of solid surface tension. J. Colloid Interface Sci. 2005, 291, 497-506. [CrossRef]

23. State Technology Supervision Administration. Industrial Circulating Cooling Water; GB/T 14643.6-93; State Technology Supervision Administration: Beijing, China, 1993.

24. Oss, C.J.V.; Good, R.J.; Chaudhury, M.K. Additive and nonadditive surface tension components and the interpretation of contact angles. Langmuir 1988, 4, 884-891.

25. Oss, C.J.V.; Ju, L.; Chaudhury, M.K.; Good, R.J. Estimation of the polar parameters of the surface tension of liquids by contact angle measurements on gels. J. Colloid Interface Sci. 1989, 128, 313-319.

26. Chen, J.; Zheng, X.; Wang, H.; Zheng, W.T. Graphene oxide-Ag nanocomposite: In situ photochemical synthesis and application as a surface-enhanced Raman scattering substrate. Thin Solid Film 2011, 520, 179-185. [CrossRef]

27. Dinh, D.A.; Hui, K.S.; Hui, K.N.; Cho, Y.R.; Zhou, W.; Hong, X.T.; Chun, H. Green synthesis of high conductivity silver nanoparticle-reduced graphene oxide composite films. Appl. Surf. Sci. 2014, 298, 62-67. [CrossRef]

28. Wu, J.X.; Xu, H.; Zhang, J. Raman spectroscopy of graphene. Acta Chim. Sin. 2014, 72, 301-318. [CrossRef]

29. Chibowski, E.; Hołysz, L.; Wójcik, W. Changes in zeta potential and surface free energy of calcium carbonate due to exposure to radiofrequency electric field. Colloids Surf. A 1994, 92, 79-85. [CrossRef]

30. Oss, C.J.V. Interfacial Forces in Aqueous Media; Marcel Dekker: New York, NY, USA, 1994.

(C) 2020 by the authors. Licensee MDPI, Basel, Switzerland. This article is an open access article distributed under the terms and conditions of the Creative Commons Attribution (CC BY) license (http://creativecommons.org/licenses/by/4.0/). 